\title{
Video-assisted thoracoscopic lobectomy versus open lobectomy in the treatment of large lung cancer: propensity-score matched analysis
}

Jeonghee Yun ${ }^{\dagger}$, Junghee Lee ${ }^{\dagger}$, Sumin Shin, Hong Kwan Kim, Yong Soo Choi, Jhingook Kim, Jae II Zo, Young Mog Shim and Jong Ho Cho*

\begin{abstract}
Background: There are several concerns on thoracoscopic surgery for large tumors because of the increased risk of tumor cell spillage. This study aimed to compare perioperative outcomes and oncological validity between video-assisted thoracoscopic surgery (VATS) and open lobectomy for non-small cell lung cancer (NSCLC) with tumor size $>5 \mathrm{~cm}$.

Methods: We retrospectively reviewed 355 patients who underwent lobectomy with clinical NO NSCLC with solid tumor component diameter $>5 \mathrm{~cm}$ between January 2009 and December 2016. Patients with tumor invading adjacent structures were excluded. The patients were divided into the VATS group $(n=132)$ and thoracotomy group ( $n=223)$. Propensity score matching (1:1) was applied.

Results: After propensity score matching, 204 patients were matched, and clinical characteristics of the two groups were well balanced. The VATS group was associated with a shorter length of hospital stay ( 6 days vs. 7 days; $P<0.001$ ) than the thoracotomy group. There were no significant differences in the 5 -year overall survival $(71.5 \%$ in VATS vs. $64.4 \%$ in thoracotomy, $P=0.390)$ and 5 -year recurrence-free survival (60.1\% in VATS vs. $51.5 \%$ in thoracotomy, $P=0.210$ ) between the two groups. The cumulative incidence of ipsilateral pleural recurrence was not significantly different between the two groups (12.0\% in VATS vs. $7.9 \%$ in thoracotomy; $P=0.582$ ).

Conclusions: In clinical NO NSCLC larger than $5 \mathrm{~cm}$, VATS lobectomy resulted in shorter hospital stay and similar survival outcome compared to open lobectomy. Based on these results, VATS lobectomy is a valuable option in this subset of patients.
\end{abstract}

Keywords: Large tumor, Non-small cell lung cancer, Video-assisted thoracoscopic surgery, Lobectomy

\section{Background}

Video-assisted thoracoscopic surgery (VATS) lobectomy is a commonly used approach in the treatment of earlystage non-small cell lung cancer (NSCLC). Numerous

\footnotetext{
*Correspondence: jongho.cho@gmail.com

† Jeonghee Yun and Junghee Lee contributed equally to this work as first authors

Department of Thoracic and Cardiovascular Surgery, Samsung Medical Center, Sungkyunkwan University School of Medicine, 81 Irwon-ro,

Gangnam-gu, Seoul 06531, South Korea
}

previous studies have shown that VATS lobectomy results in less pain, shorter hospital stay, and better postoperative quality of life compared with thoracotomy lobectomy, without compromising oncological outcomes [1-5]. The National Comprehensive Cancer Network guidelines recommend this approach in patients without anatomic or surgical contraindications [6].

With advances in surgical technique, the indication for VATS has been expanding to locally advanced NSCLC. However, surgeons still hesitate to perform thoracoscopic original author(s) and the source, provide a link to the Creative Commons licence, and indicate if changes were made. The images or other third party material in this article are included in the article's Creative Commons licence, unless indicated otherwise in a credit line to the material. If material is not included in the article's Creative Commons licence and your intended use is not permitted by statutory regulation or exceeds the permitted use, you will need to obtain permission directly from the copyright holder. To view a copy of this licence, visit http://creativecommons.org/licenses/by/4.0/. The Creative Commons Public Domain Dedication waiver (http://creativeco mmons.org/publicdomain/zero/1.0/) applies to the data made available in this article, unless otherwise stated in a credit line to the data. 
surgery on large tumors because thoracoscopic manipulation of large tumors is challenging and extraction of large tumors through a small incision may increase the risk of tumor rupture or cancer cell spillage [7]. Moreover, there is another concern regarding the adequacy of mediastinal lymph node assessment of VATS lobectomy, as larger tumors have more unexpected lymph node metastases [8-13].

Several studies have investigated the safety and efficacy of VATS lobectomy for NSCLC with tumor size $>5 \mathrm{~cm}$. These studies showed that short- and long-term overall survival (OS) was not different between VATS and thoracotomy for patients with NSCLC with tumor size $>5 \mathrm{~cm}$ $[14,15]$. However, these studies had a small sample size, heterogeneous population between treatment groups, and no information on cancer recurrence. Therefore, this study aimed to compare long-term OS and recurrencefree survival (RFS) between VATS lobectomy and thoracotomy lobectomy for NSCLC with tumor size $>5 \mathrm{~cm}$ after propensity score matching. Moreover, we measured the solid component diameter of the tumor to define clinical tumor size because this measurement better predicts prognosis than the total tumor size [16-20].

\section{Methods}

\section{Study cohort}

The data were obtained from a prospectively maintained institutional lung cancer database in Samsung Medical Center. A total of 5459 patients underwent curative lobectomy for primary NSCLC at Samsung Medical Center between January 2009 and December 2016. Of 4360 patients with clinical NO NSCLC, patients with solid tumor component diameter $>5 \mathrm{~cm}$ on computed tomography (CT) were enrolled. Patients who had the following features were excluded from the study cohort: preoperative treatment with chemotherapy or radiation, primary tumor that invaded to adjacent structures (chest wall, pericardium, diaphragm, mediastinum, or esophagus), requirement of angioplasty or bronchoplasty, and another surgical approach other than thoracotomy or VATS (e.g., median sternotomy, transmanubrial approach). The study cohort was divided into the VATS group and thoracotomy group according to the initial intent (Additional file 1: Fig. 1). This retrospective study was approved by the ethics committee of the Samsung Medical Center, and informed consent was waived (Institutional Review Board number: SMC 2020-01-079).

\section{Staging workup}

In this study, preoperative staging was performed in accordance with the American Joint Committee on Cancer (AJCC) Cancer Staging Manual, 7th edition, and patients' TNM stage was reclassified according to the AJCC Cancer Staging Manual, 8th edition. The routine preoperative workup included chest $\mathrm{CT}$, integrated whole-body 18F-fluorodeoxyglucose positron emission tomography and $\mathrm{CT}$, and brain magnetic resonance imaging. In patients with suspicious nodal involvement, pathological confirmation of the suspected node was performed through endobronchial ultrasound-guided transbronchial needle aspiration or mediastinoscopy [21, 22].

\section{Surgical strategy and follow-up}

Generally, VATS lobectomy was performed under singlelung anesthesia, using two ports and utility incision without rib spreading [1]. A 4-cm utility incision was made through the fifth or sixth intercostal space in the middle axillary line. Two additional ports were placed through the fourth or fifth intercostal space in the anterior and posterior axillary lines. However, details of the surgical techniques of VATS lobectomy varied among surgeons, as each surgeon has modified the technique according to their preferences.

The oncological principles remained the same regardless of the surgical approach: (1) the vessels and bronchi of the target lobe were individually dissected, (2) systematic lymph node dissection was regarded as mandatory, and (3) touching the lymph node itself and rupturing the capsule of the lymph node were avoided [1]. All specimens were placed into an impermeable bag and removed through the utility incision.

Patients were strictly followed every 3 months for the first 2 years postoperatively and every 6 months thereafter and underwent $\mathrm{CT}$ annually. Patients were also evaluated regularly via a history assessment, physical examination, blood tests, and chest radiography at each visit. Whole-brain $\mathrm{CT}$ or brain magnetic resonance imaging and other imaging techniques were performed as indicated, based on the patient's symptoms.

\section{Statistical analysis}

The primary outcome of this study was OS, defined as the time from surgery to death from any cause or last follow-up date. Secondary outcomes of this study were length of hospital stay, 30-day morbidity and mortality, ipsilateral pleural recurrence, and RFS, defined as time from surgery to recurrence or last recurrence surveillance confirming no evidence of recurrence. Locoregional recurrence was defined as that occurring within the surgical field, including the bronchial stump, pleural space, and regional lymph nodes. Distant recurrence was defined as that occurring beyond the surgical field that was not resected in the primary surgery.

Baseline characteristics and unadjusted outcomes were analyzed using the Wilcoxon rank sum test for continuous variables, and the chi-square test for 
categorical variables. Propensity score matching (1:1) was applied to reduce the effects of observed confounding between the two groups. As surgical planning is decided based on the findings of the clinical staging assessment, we used clinical variables for propensityscore matched analysis. Age, sex, tumor size, histology, pulmonary function test (forced expiratory volume in $1 \mathrm{~s}$, diffusing capacity of lung for carbon monoxide), and Charlson comorbidity index were selected as covariates for propensity score analysis. Standardized mean differences were used to confirm a balanced matching result (Additional file 3: Table S1). When the standardized mean difference was $<0.1$, we considered the matched values to be well balanced. For the matched cohort, baseline characteristics and perioperative outcomes were analyzed using the Wilcoxon signed rank test and McNemar test.

The Kaplan-Meier method and log-rank test were used to compare OS and RFS. Competing risk analysis and Gray's method were used to assess and compare the cumulative incidence rate of recurrence in each recurrence pattern and ipsilateral pleural recurrence rate. Death or not-interested recurrence patterns were regarded as competing risks. A multivariate Cox proportional hazard analysis for OS was performed using covariates, which showed a P-value $<0.1$ in univariate Cox proportional hazard analysis. A P-value $<0.05$ was considered statistically significant.

\section{Results}

\section{Study cohort}

The study cohort consisted of 355 patients with clinical NO NSCLC with solid tumor component diameters $>5 \mathrm{~cm}$ on chest CT. A total of $132(37.2 \%)$ patients were assigned to the VATS group and 223 (62.8\%) patients were assigned to the thoracotomy group. There were more women $(27.3 \%$ in the VATS group vs $12.1 \%$ in the thoracotomy group; $P<0.001)$ and never-smokers (32.6\% in the VATS group vs $12.1 \%$ in the thoracotomy group; $P<0.001)$ in the VATS group. The median clinical tumor size was $57 \mathrm{~mm}$ (interquartile range [IQR], 54-65) in the VATS group and $61 \mathrm{~mm}$ (IQR, 55-75) in thoracotomy group $(P<0.001)$. The most common histology was adenocarcinoma $(66.7 \%)$ in the VATS group but squamous cell carcinoma $(48.4 \%)$ in the thoracotomy group $(P<0.001)$.

After propensity score matching, 204 patients were available for analysis. The median clinical tumor size was $67 \mathrm{~mm}$ (IQR, 60-72) in the VATS group and $67 \mathrm{~mm}$ (IQR, 61-72) in the thoracotomy group $(P=0.871)$. The VATS and thoracotomy groups were well balanced for demographic and clinical characteristics (Table 1).

\section{Perioperative outcomes}

There were 10 conversions to thoracotomy from VATS: six were due to diffuse tight pleural adhesion, and four were due to anthracofibrotic lymph node around the pulmonary artery.

In the unmatched cohort, the median pathologic tumor size was $55 \mathrm{~mm}$ (IQR, 45-64.5) in the VATS group and $60 \mathrm{~mm}$ (IQR, 52.5-74) in thoracotomy group $(P<0.001)$. The VATS group had a shorter hospital stay than the thoracotomy group ( 6 days [ $5-8$ days] vs 8 days [6-11 days]; $P<0.001$ ). The 30 -day morbidity and mortality did not show any significant differences between the two groups. In the propensity score-matched cohort, the median pathologic tumor size was $56 \mathrm{~mm}$ (IQR, 48-65) in the VATS group and $55.5 \mathrm{~mm}$ (IQR, 50-65) in the thoracotomy group $(P=0.348)$. The VATS group had a shorter hospital stay than the thoracotomy group ( 6 days [5-8 days] vs 7 days [6-10 days]; $P<0.001$ ), whereas there were no differences in the 30-day morbidity and mortality (Table 2). The detailed information regarding complications within 30 days is shown in Table 3 . In the unmatched cohort, the VATS group showed a lower incidence of pneumonia $(0.8 \%$ vs $5.8 \% ; P=0.018)$ and arrhythmia $(9.1 \%$ vs $17.9 \% ; P=0.023)$ than the thoracotomy group. Conversely, in the propensity score-matched cohort, the incidence of pneumonia was not significantly different ( $4.9 \%$ vs $0 \% ; P=0.064$ ) between the two groups, but the incidence of arrhythmia was still significantly lower in the VATS group than in the thoracotomy group (8.1\% vs $21.6 \%$; $P=0.005)$.

\section{Survival outcomes}

The median follow-up period of the entire cohort was 80 months. At the completion of the study, 134 patients died, and 130 patients had recurrence during the followup. In the VATS group, 33 patients died, and 44 patients had recurrence, while, in the thoracotomy group, 101 patients died, and 86 patients had recurrence. The 5-year OS rates were $75.5 \%$ in the VATS group and $56.1 \%$ in the thoracotomy group. The log-rank test showed that the VATS group had significantly superior OS compared with the thoracotomy group $(P<0.001)$. In contrast, the 5 -year RFS rates was not significantly different between the groups $(59.8 \%$ in the VATS group vs. $50.6 \%$ in the thoracotomy group, $P=0.160$ ) (Fig. 1a).

After propensity score matching, the 5-year OS rates were $71.5 \%$ in the VATS group and $64.4 \%$ in the thoracotomy group. The 5 -year RFS rates were $60.1 \%$ in the VATS group and $51.5 \%$ in the thoracotomy group. There were no significant differences in the OS and RFS between the VATS and thoracotomy groups (OS, $P=0.390$; RFS, $P=0.210$ ) (Fig. 1b). Additional survival analysis was 
Table 1 Baseline characteristics

\begin{tabular}{|c|c|c|c|c|c|c|}
\hline \multirow[t]{2}{*}{ Variables } & \multicolumn{3}{|l|}{ Unmatched cohort } & \multicolumn{3}{|c|}{ Propensity score-matched cohort } \\
\hline & Thoracotomy $(n=223)$ & VATS $(n=132)$ & $P$ value & Thoracotomy $(n=102)$ & VATS $(n=102)$ & $P$ value \\
\hline Age & $68(61.0-73.0)$ & $66(59.8-71.0)$ & 0.139 & $67(61.0-72.0)$ & $67(60.0-72.0)$ & 0.871 \\
\hline \multicolumn{7}{|l|}{$\operatorname{sex}$} \\
\hline Female & $27(12.1 \%)$ & $36(27.3 \%)$ & $<0.001$ & $17(16.7 \%)$ & $18(17.6 \%)$ & $>0.999$ \\
\hline Male & $196(87.9 \%)$ & $96(72.7 \%)$ & & $85(83.3 \%)$ & $84(82.4 \%)$ & \\
\hline \multicolumn{7}{|l|}{ Smoking } \\
\hline Never & $27(12.1 \%)$ & $43(32.6 \%)$ & $<0.001$ & $19(18.6 \%)$ & $25(24.5 \%)$ & 0.829 \\
\hline Former & $102(45.7 \%)$ & $55(41.7 \%)$ & & $44(43.1 \%)$ & $47(46.1 \%)$ & \\
\hline Current & $94(42.1 \%)$ & $34(25.8 \%)$ & & $39(38.2 \%)$ & $30(29.4 \%)$ & \\
\hline \multicolumn{7}{|l|}{ FEV1 (\%) } \\
\hline$\geq 80 \%$ & $51(22.9 \%)$ & $20(15.2 \%)$ & 0.079 & $81(79.4 \%)$ & $84(82.4 \%)$ & 0.701 \\
\hline$<80 \%$ & $172(77.1 \%)$ & $112(84.9 \%)$ & & $21(20.6 \%)$ & $18(17.6 \%)$ & \\
\hline \multicolumn{7}{|l|}{ DLCO (\%) } \\
\hline$\geq 80 \%$ & $26(11.7 \%)$ & $8(6.1 \%)$ & 0.083 & 91 (89.2\%) & 94 (92.2\%) & 0.607 \\
\hline$<80 \%$ & 197 (88.3\%) & 124 (93.9\%) & & $11(10.8 \%)$ & $8(7.8 \%)$ & \\
\hline \multicolumn{7}{|l|}{$\mathrm{CCl}$} \\
\hline 0 & 146 (65.5\%) & $88(66.7 \%)$ & 0.627 & $66(64.7 \%)$ & $64(62.7 \%)$ & 0.809 \\
\hline 1 & $49(22.0 \%)$ & 31 (23.5\%) & & $26(25.5 \%)$ & $27(26.5 \%)$ & \\
\hline 2 & 18 (8.1\%) & $6(4.5 \%)$ & & $5(4.9 \%)$ & $5(4.9 \%)$ & \\
\hline$\geq 3$ & $10(4.5 \%)$ & $7(5.3 \%)$ & & $5(4.9 \%)$ & $6(5.9 \%)$ & \\
\hline Tumor size & $61(55.0-75.0)$ & $57(54.0-65.0)$ & $<0.001$ & $59(54.3-68.5)$ & $59(54.0-67.0)$ & 0.777 \\
\hline \multicolumn{7}{|l|}{ Location } \\
\hline RUL & $53(23.8 \%)$ & $29(22.0 \%)$ & 0.060 & $20(19.6 \%)$ & $22(21.6 \%)$ & 0.106 \\
\hline RML & $2(0.9 \%)$ & $7(5.3 \%)$ & & $2(2 \%)$ & $7(6.9 \%)$ & \\
\hline RLL & $54(24.2 \%)$ & $40(30.3 \%)$ & & $25(24.5 \%)$ & $32(31.4 \%)$ & \\
\hline LUL & $56(25.1 \%)$ & $26(19.7 \%)$ & & $26(25.5 \%)$ & $20(19.6 \%)$ & \\
\hline LLL & $58(26.0 \%)$ & $30(22.7 \%)$ & & $29(28.4 \%)$ & $21(20.6 \%)$ & \\
\hline \multicolumn{7}{|l|}{ Histology } \\
\hline$A D C$ & $90(40.4 \%)$ & 88 (66.7\%) & $<0.001$ & $62(60.8 \%)$ & $63(61.8 \%)$ & $>0.999$ \\
\hline SCC & 108 (48.4\%) & $30(22.7 \%)$ & & $28(27.5 \%)$ & $26(25.5 \%)$ & \\
\hline Others & 25 (11.21\%) & $14(10.61 \%)$ & & $12(11.8 \%)$ & $13(12.7 \%)$ & \\
\hline
\end{tabular}

Data are presented as number (\%), or median (interquartile range)

FEV1 forced expiratory volume at $1 \mathrm{~s}, D L C O$ diffusing capacity for carbon monoxide, CCI Charlson comorbidity index, $A D C$ adenocarcinoma, SCC squamous cell carcinoma, VATS video-assisted thoracic surgery

performed in the subgroups of the matched cohort. In the subgroups stratified by pathologic lymph node metastasis, there were no statistically significant differences in OS between the VATS and thoracotomy groups (Additional file 2: Fig. 2a). Similarly, no significant survival differences were observed in subgroups stratified by tumor histology (Additional file 2: Fig. 2b).

In the multivariate Cox proportional hazard model analysis for OS, surgical approach (VATS vs. thoracotomy) was not an independent risk factor for survival (hazard ratio, 0.76; 95\% confidence interval, 0.51-1.15; $P=0.195)$ after adjusting for sex, age, Charlson comorbidity index, pathologic tumor size, pathologic lymph node metastasis, tumor histology, and adjuvant therapy (Table 4).

\section{Recurrence patterns}

Of the 130 patients with recurrence, locoregional recurrence occurred in 22 patients, distant recurrence occurred in 86 patients, and ipsilateral pleural recurrence occurred in 24 patients (Additional file 3: Table 2). The cumulative incidence rate (CIR) of locoregional recurrence at 5 years was $6.4 \%$ in the VATS group and $9.1 \%$ in the thoracotomy group (Gray's test, $P=0.260$ ). The CIR of distant metastasis was similar between the two groups ( $26.6 \%$ vs $32.3 \% ; P=0.429)$. No differences were observed 
Table 2 Perioperative outcomes

\begin{tabular}{|c|c|c|c|c|c|c|}
\hline \multirow[t]{2}{*}{ Variables } & \multicolumn{3}{|l|}{ Unmatched cohort } & \multicolumn{3}{|c|}{ Propensity score-matched cohort } \\
\hline & Thoracotomy $(n=223)$ & VATS $(n=132)$ & $P$ value & Thoracotomy $(n=102)$ & VATS $(n=102)$ & $P$ value \\
\hline Harvested LN number & $22(16.0-30.0)$ & $16(12.0-22.0)$ & $<0.001$ & $22.5(17.0-29.8)$ & $16(11.0-22.8)$ & $<0.001$ \\
\hline \multicolumn{7}{|l|}{ Bronchial margin } \\
\hline RO & $222(99.6 \%)$ & $132(100 \%)$ & $>0.999$ & $111(100 \%)$ & $111(100 \%)$ & $>0.999$ \\
\hline $\mathrm{R} 1$ & $1(0.4 \%)$ & $0(0.0 \%)$ & & $0(0 \%)$ & $0(0 \%)$ & \\
\hline Hospital length of stay & $8(6.0-11.0)$ & $6(5.0-8.0)$ & $<0.001$ & $7(6.0-10.0)$ & $6(5.0-8.0)$ & $<0.001$ \\
\hline 30-day morbidity & $94(42.2 \%)$ & $42(31.8 \%)$ & 0.053 & $41(40.2 \%)$ & $32(31.4 \%)$ & 0.188 \\
\hline 30-day mortality & $2(0.9 \%)$ & $0(0.0 \%)$ & 0.147 & $1(1 \%)$ & $0(0 \%)$ & $>0.999$ \\
\hline Pathologic tumor size & $60(52.5-74)$ & $55(45-64.5)$ & $<0.001$ & $55.5(50-65)$ & $56(48-65)$ & 0.348 \\
\hline \multicolumn{7}{|l|}{ Pathologic N stage } \\
\hline pNO & 169 (75.8\%) & $106(80.3 \%)$ & 0.147 & $72(70.6 \%)$ & $86(84.3 \%)$ & 0.143 \\
\hline $\mathrm{pN1}$ & $29(13.0 \%)$ & $9(6.8 \%)$ & & $18(17.6 \%)$ & $5(4.9 \%)$ & \\
\hline pN2 & $25(11.2 \%)$ & $16(12.1 \%)$ & & $12(11.8 \%)$ & $11(10.8 \%)$ & \\
\hline Visceral pleural invasion & $38(17.0 \%)$ & $28(21.2 \%)$ & 0.404 & $25(24.5 \%)$ & $23(22.5 \%)$ & 0.864 \\
\hline \multicolumn{7}{|l|}{ Adjuvant treatment } \\
\hline No adjuvant treatment & $93(41.7 \%)$ & $65(49.2 \%)$ & 0.204 & $43(42.2 \%)$ & $53(52 \%)$ & 0.262 \\
\hline Chemotherapy & 110 (49.3\%) & $62(47 \%)$ & & $52(51 \%)$ & $46(45.1 \%)$ & \\
\hline Radiotherapy & $7(3.1 \%)$ & $1(0.7 \%)$ & & $1(1 \%)$ & $1(1 \%)$ & \\
\hline Chemoradiotherapy & $13(5.8 \%)$ & $4(3 \%)$ & & $6(5.9 \%)$ & $2(2 \%)$ & \\
\hline
\end{tabular}

Data are presented as number (\%) or median (interquartile range)

Table 3 Complications within 30 days

\begin{tabular}{|c|c|c|c|c|c|c|}
\hline \multirow[t]{2}{*}{ Complications } & \multicolumn{3}{|l|}{ Unmatched cohort } & \multicolumn{3}{|c|}{ Propensity score-matched cohort } \\
\hline & Thoracotomy $(n=223)$ & VATS $(n=132)$ & $P$ value & $\begin{array}{l}\text { Thoracotomy } \\
(n=102)\end{array}$ & VATS $(n=102)$ & $P$ value \\
\hline Number of patients & $94(42.2 \%)$ & $42(31.8 \%)$ & 0.053 & $41(40.2 \%)$ & $32(31.4 \%)$ & 0.188 \\
\hline Number of events & $119(53.4 \%)$ & $48(36.4 \%)$ & & $92(90.2 \%)$ & $61(59.8 \%)$ & \\
\hline Pulmonary & $41(18.4 \%)$ & $23(17.4 \%)$ & 0.820 & $16(15.7 \%)$ & $20(19.6 \%)$ & 0.585 \\
\hline Pneumonia/empyema & $13(5.8 \%)$ & $1(0.8 \%)$ & 0.018 & $5(4.9 \%)$ & $0(0 \%)$ & 0.063 \\
\hline ARDS & $7(3.1 \%)$ & $4(3 \%)$ & $>0.999$ & $2(2 \%)$ & $4(3.9 \%)$ & 0.687 \\
\hline Prolonged air leak/pneumothorax & $16(7.2 \%)$ & $16(12.1 \%)$ & 0.116 & $8(7.8 \%)$ & $15(14.7 \%)$ & 0.167 \\
\hline Secretion retention/atelectasis & $4(1.8 \%)$ & $0(0 \%)$ & 0.301 & $1(1 \%)$ & $0(0 \%)$ & $>0.999$ \\
\hline Others* & $1(0.4 \%)$ & $2(1.5 \%)$ & 0.558 & $0(0 \%)$ & $1(1 \%)$ & $>0.999$ \\
\hline Cardiac & $41(18.4 \%)$ & $12(9.1 \%)$ & 0.018 & $21(20.6 \%)$ & $6(5.9 \%)$ & 0.003 \\
\hline Arrhythmia & $40(17.9 \%)$ & $12(9.1 \%)$ & 0.023 & $20(19.6 \%)$ & $6(5.9 \%)$ & 0.004 \\
\hline $\mathrm{Ml}$ & $1(0.4 \%)$ & $0(0 \%)$ & $>0.999$ & $1(1 \%)$ & $0(0 \%)$ & $>0.999$ \\
\hline CVA & $6(2.7 \%)$ & $1(0.8 \%)$ & 0.265 & $3(2.9 \%)$ & $1(1 \%)$ & 0.625 \\
\hline Bleeding & $1(0.4 \%)$ & $2(1.5 \%)$ & 0.558 & $0(0 \%)$ & $1(1 \%)$ & $>0.999$ \\
\hline Wound dehiscence & $4(1.8 \%)$ & $1(0.8 \%)$ & 0.655 & $3(2.9 \%)$ & $1(1 \%)$ & 0.625 \\
\hline Others** & $26(11.7 \%)$ & $9(6.8 \%)$ & 0.139 & $12(11.8 \%)$ & $6(5.9 \%)$ & 0.180 \\
\hline
\end{tabular}

Data are presented as number (\%)

ARDS acute respiratory distress syndrome, $M /$ myocardial infarction

*Other pulmonary complications include pleural effusion and acute exacerbation of chronic obstructive pulmonary disease

**Other complications include delirium, chylothorax, ileus, vocal cord palsy, and urinary tract infection 

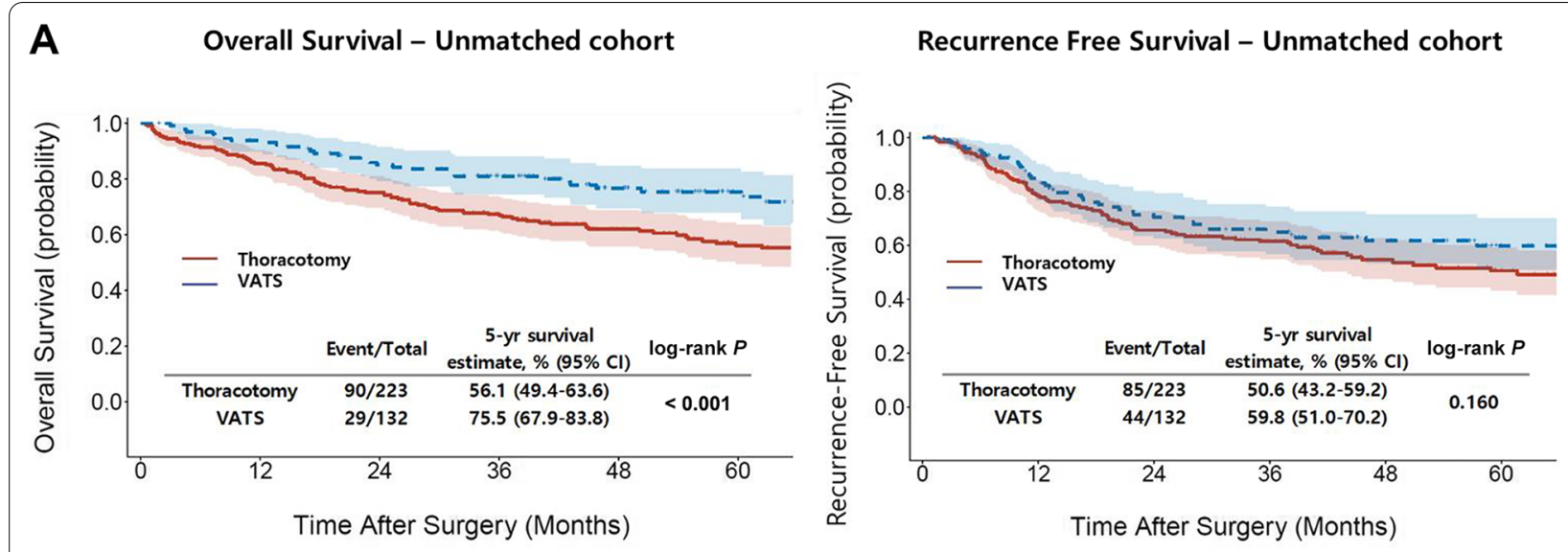

\begin{tabular}{|c|c|c|c|c|c|}
\hline 223 & 191 & 164 & 138 & 94 & 68 \\
\hline 132 & 122 & 105 & 90 & 64 & 41 \\
\hline
\end{tabular}

\section{B Overall Survival - Matched cohort}

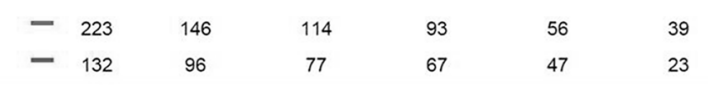
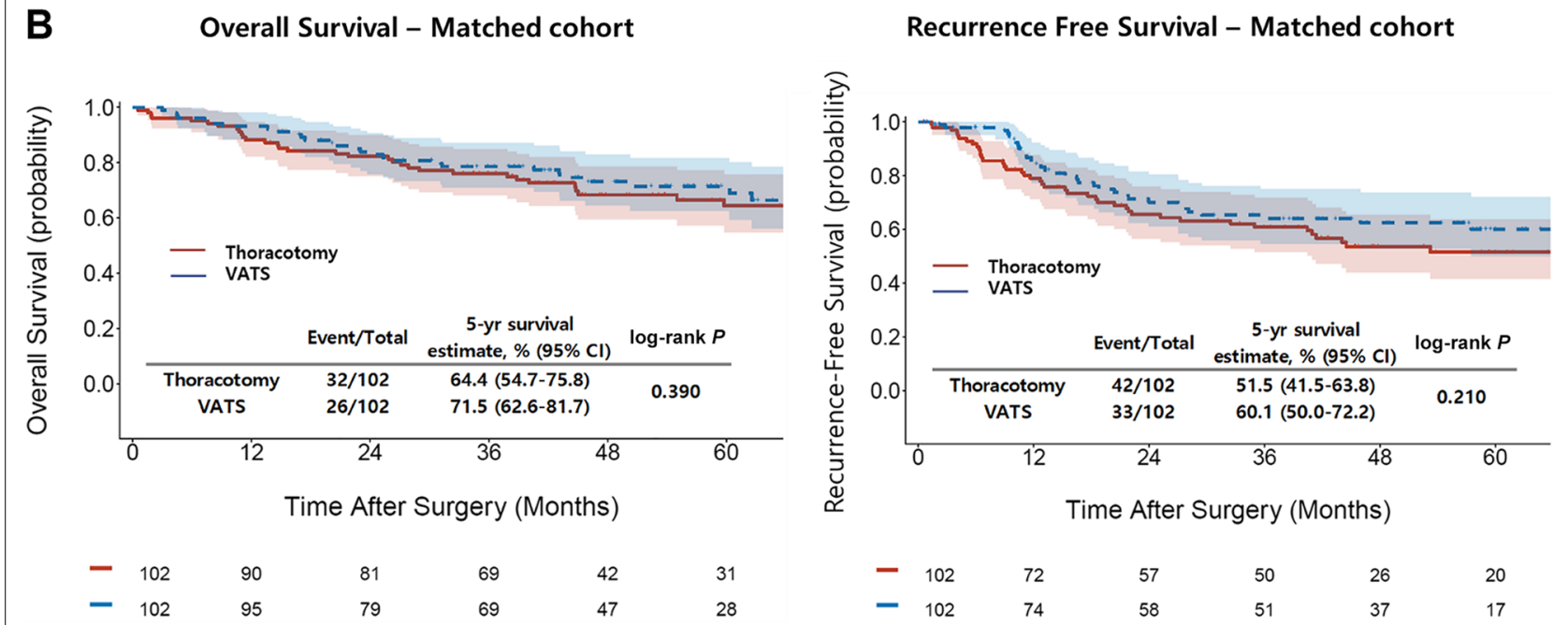

Fig. 1 Survival outcomes. Kaplan-Meier estimation of VATS group showed better overall survival and similar recurrence-free survival than the thoracotomy group in unmatched cohort. a After propensity score matching (1:1), the survival curve showed that there were no significant differences in overall and recurrence-free survivals between the VATS and thoracotomy groups. b VATS, video-assisted thoracoscopic surgery; Cl, confidence interval

in the CIR of locoregional recurrence and distant metastasis after propensity matching $(P=0.679$ and $P=0.364$, respectively) (Fig. 2). The VATS group did not show an increased risk of ipsilateral pleural recurrence in the unmatched cohort (10.1\% in the VATS group vs. $7.7 \%$ in the thoracotomy group, $P=0.737$ ) and matched cohort $(12.0 \%$ in the VATS group vs. $7.9 \%$ in the thoracotomy group, 0.582 ).

\section{Discussion}

Thoracoscopic surgery for large tumor is challenging because a large tumor interferes with the surgeon's delicate movements, which can sometimes lead to vessel injury or tumor rupture. It is technically more difficult to obtain sufficient resection margin in VATS than in thoracotomy when a large tumor is centrally located. Moreover, extraction of the large tumor via small incision can crush the tumor or tear the extraction bag. Theoretically, these may increase ipsilateral pleural recurrence or locoregional recurrence. However, the current study showed that VATS lobectomy did not increase ipsilateral pleural recurrence or locoregional recurrence compared to thoracotomy, and the 5-year RFS was not different between the two groups. Moreover, VATS lobectomy demonstrated benefit in the early postoperative period. The length of hospital stay was significantly reduced, and postoperative pneumonia and arrythmia less occurred in the VATS group. It shows that the technical difficulty of 
Table 4 Multivariable Cox proportional hazard model for OS in unmatched cohort

\begin{tabular}{|c|c|c|c|c|c|c|c|c|}
\hline \multirow[t]{2}{*}{ Variable } & \multicolumn{4}{|c|}{ Univariable analysis } & \multicolumn{4}{|c|}{ Multivariable analysis } \\
\hline & Hazard ratio & $95 \% \mathrm{Cl}$ & & $P$ value & Hazard ratio & $95 \% \mathrm{Cl}$ & & $P$ value \\
\hline $\begin{array}{l}\text { VATS (vs. } \\
\text { thoracotomy) }\end{array}$ & 0.56 & 0.38 & 0.82 & 0.003 & 0.81 & 0.54 & 1.23 & 0.331 \\
\hline $\begin{array}{l}\text { Sex, male (vs. } \\
\text { female) }\end{array}$ & 2.23 & 1.28 & 3.88 & 0.005 & 1.65 & 0.93 & 2.95 & 0.087 \\
\hline Age (per year) & 1.05 & 1.03 & 1.08 & $<0.001$ & 1.04 & 1.02 & 1.07 & $<0.001$ \\
\hline $\begin{array}{l}\mathrm{CCl} \geq 2 \text { (vs. } \\
\mathrm{CCl}<2)\end{array}$ & 2.10 & 1.34 & 3.30 & 0.001 & 1.72 & 1.09 & 2.74 & 0.021 \\
\hline $\begin{array}{l}\text { FEV1 } \geq 80 \% \\
\text { (vs. }<80 \% \text { ) }\end{array}$ & 1.02 & 0.66 & 1.56 & 0.935 & & & & \\
\hline $\begin{array}{l}\mathrm{DLCO} \geq 80 \% \\
\text { (vs. }<80 \%)\end{array}$ & 0.77 & 0.45 & 1.32 & 0.349 & & & & \\
\hline $\begin{array}{l}\text { Pathologic } \\
\text { tumor size }\end{array}$ & 1.02 & 1.01 & 1.03 & $<0.001$ & 1.02 & 1.01 & 1.03 & $<0.001$ \\
\hline $\begin{array}{l}\text { Pathologic } \\
N+\text { (vs. pNO) }\end{array}$ & 1.90 & 1.32 & 2.75 & 0.001 & 2.33 & 1.60 & 3.40 & $<0.001$ \\
\hline $\begin{array}{l}\text { Histology } \\
\text { (ref=ADC) }\end{array}$ & & & & 0.009 & & & & \\
\hline SCC & 1.65 & 1.16 & 2.36 & & 1.13 & 0.77 & 1.65 & 0.542 \\
\hline Others & 0.87 & 0.46 & 1.66 & & 0.86 & 0.44 & 1.65 & 0.643 \\
\hline $\begin{array}{l}\text { Adjuvant } \\
\text { treatment }\end{array}$ & 0.65 & 0.47 & 0.92 & 0.013 & 0.69 & 0.47 & 1.03 & 0.071 \\
\hline
\end{tabular}

Statistically significant variates $(P<0.1)$ in the univariable analysis were used as covariates for multivariable analysis

VATS video-assisted thoracic surgery, CCI Charlson comorbidity index, FEV 1 forced expiratory volume at $1 \mathrm{~s}, D L C O$ diffusing capacity for carbon monoxide, $A D C$ adenocarcinoma, SCC squamous cell carcinoma
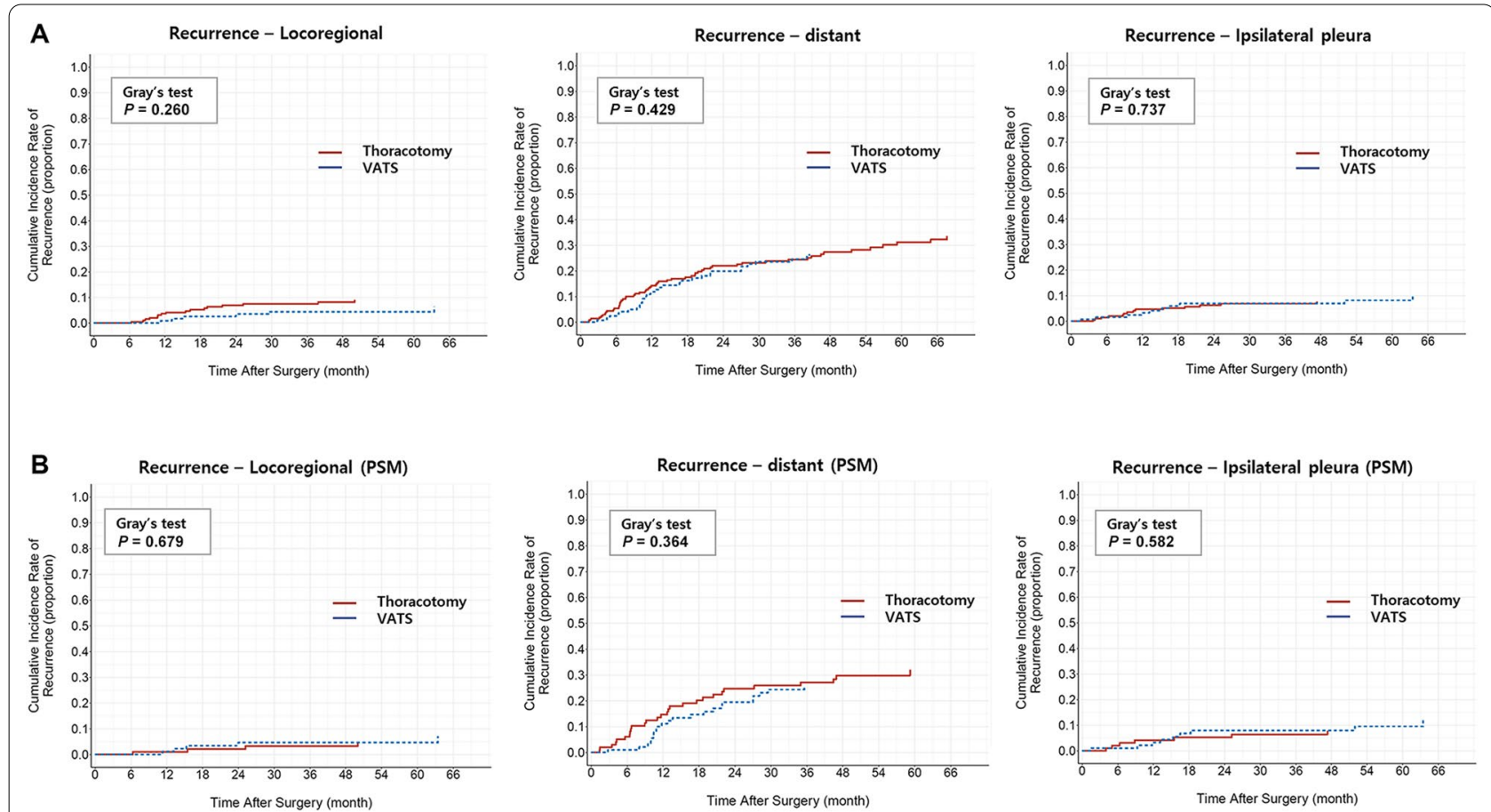

Fig. 2 Cumulative incidence of recurrence. Cumulative incidence of locoregional, distant, and ipsilateral pleural recurrences were not different between VATS and thoracotomy groups in both unmatched (a) and matched cohorts (b) 
VATS lobectomy did not adversely affect the postoperative and long-term survival outcomes in large lung tumor.

Another concern on VATS lobectomy for large lung tumor is the adequacy of mediastinal lymph node assessment. Although many previous studies have shown that the number of removed lymph nodes by VATS was not inferior to open thoracotomy in early lung cancer $[4,23-$ 27] and a recent study showed no difference in pathological nodal upstaging rate between VATS and thoracotomy even in clinical N1 NSCLC [28], concerns still remain on the adequacy of thoracoscopic lymph node assessment in clinical stage II lung cancer. In this study, although more lymph nodes were harvested in the thoracotomy group, the number of harvested lymph nodes in the VATS group was sufficient to meet the requirement of the 8th edition of the AJCC Cancer Staging Manual, which recommends removal of at least six lymph nodes [29]. Moreover, the pathologic nodal upstaging rate and incidence of regional lymph node recurrence were not statistically different between the VATS and thoracotomy groups. Moreover, long-term survival was not different between VATS and thoracotomy groups in the subgroup stratified by pathologic nodal upstaging (Additional file 2: Fig. 2a). It indicates that thoracoscopic lymph node dissection does not reduce the quality of lymph node dissection in large lung cancer.

The notable point in this study is that we measured clinical tumor size according to the TNM cancer staging system 8th edition that was revised to measure the solid tumor diameter rather than the total diameter to describe the $\mathrm{T}$ stage. Previous studies measured total diameter to determine the tumor size and had no information on consolidation to tumor ratio. However, it can create an error because solid tumor has a worse prognosis than part-solid or pure ground glass opacity tumor even if they have the same total diameter, and the treatment group including more solid tumor may have worse survival outcome. By measuring the solid diameter for tumor size and using propensity score analysis, the compounding factors were better controlled compared to those in previous studies. Moreover, the current study has the largest number of patients $(n=355)$ among related studies.

The present study has several limitations. First, the retrospective nature of this study allows the possibility of uncontrolled confounding, although propensity score matching was used to balance the variables that may influence the outcomes between the groups. Second, selection of surgical approach depends on the extent of disease in general, but the individual surgeon's preferences may also have influenced the decision. Lastly, the results of this study are results from experienced surgeon and cannot be generalized to beginners. Despite these limitations, this study showed the efficacy of VATS lobectomy in clinical stage II lung cancer and may be used as a reference for larger prospective studies.

\section{Conclusions}

In patients with clinical NO NSCLC with tumor diameter $>5 \mathrm{~cm}$, VATS lobectomy demonstrated a shorter hospital stay and similar survival outcome compared with open lobectomy after propensity score matching. Based on these results, VATS lobectomy is a valuable option in this subset of patients.

\section{Abbreviations \\ VATS: Video-assisted thoracoscopic surgery; NSCLC: Non-small cell lung can- cer; RFS: Recurrence-free survival; OS: Overall survival; AJCC: American Joint Committee on Cancer; FEV1: Forced expiratory volume in $1 \mathrm{~s}$; DLCO: Diffusing capacity of lung for carbon monoxide; CIR: Cumulative incidence rate; $\mathrm{CCl}$ : Charlson comorbidity index; ADC: Adenocarcinoma; SCC: Squamous cell carci- noma; ARDS: Acute respiratory distress syndrome; MI: Myocardial infarction.}

\section{Supplementary Information}

The online version contains supplementary material available at https://doi. org/10.1186/s13019-021-01749-8.

Additional file 1: Figure 1. Flow diagram of study cohort.

Additional file 2: Figure 2. Overall survival of the subgroup in the propensity matched cohort. (a) Overall survival of pNO patients in the matched cohort. (b) Overall survival of $\mathrm{pN}+$ patients in the matched cohort. (c) Overall survival of patients with adenocarcinoma in the matched cohort. (d) Overall survival of patients with squamous cell carcinoma in the matched cohort.

Additional file 3: Table 1. Standard mean difference of matched variables. Table 2 Pattern of recurrence.

\section{Acknowledgements}

None

\section{Data Sharing Statement}

The datasets used and/or analysed during the current study are available from the corresponding author on reasonable request.

\section{Authors' contributions}

$J H C, J Y, J L$ designed the project. SS, HKK, YSC, JK, JIZ, YMS, were involved in data collection. JHC, JY, JL analyzed and interpreted the patient data and wrote the paper. All authors read and approved the final manuscript.

\section{Funding}

This research did not receive any specific grant from funding agencies in the public, commercial, or not-for-profit sectors.

\section{Declarations}

\section{Ethics approval and consent to participate}

The authors are accountable for all aspects of the work in ensuring that questions related to the accuracy or integrity of any part of the work are appropriately investigated and resolved. This retrospective study was approved by the ethics committee of the Samsung Medical Center, and informed consent was waived (Institutional Review Board number: SMC 2020-01-079).

Consent for publication

All authors consent to the publication of the manuscript in Journal of Cardiothoracic Surgery 


\section{Competing interests}

All authors declare that they have no competing interests.

Received: 26 April 2021 Accepted: 28 December 2021

Published online: 08 January 2022

\section{References}

1. Kim K, Kim HK, Park JS, Chang SW, Choi YS, Kim J, et al. Video-assisted thoracic surgery lobectomy: single institutional experience with 704 cases. Ann Thorac Surg. 2010;89(6):S2118-22. https://doi.org/10.1016/j. athoracsur.2010.03.017.

2. Whitson BA, Groth SS, Duval SJ, Swanson SJ, Maddaus MA. Surgery for early-stage non-small cell lung cancer: a systematic review of the video-assisted thoracoscopic surgery versus thoracotomy approaches to lobectomy. Ann Thorac Surg. 2008;86(6):2008-16. https://doi.org/10. 1016/j.athoracsur.2008.07.009 (discussion 2016-8).

3. Stephens N, Rice D, Correa A, Hoffstetter W, Mehran R, Roth J, et al. Thoracoscopic lobectomy is associated with improved short-term and equivalent oncological outcomes compared with open lobectomy for clinical Stage I non-small-cell lung cancer: a propensity-matched analysis of 963 cases. Eur J Cardiothorac Surg. 2014;46(4):607-13. https://doi.org/10.1093/ejcts/ezu036.

4. Scott WJ, Allen MS, Darling G, Meyers B, Decker PA, Putnam JB, et al. Video-assisted thoracic surgery versus open lobectomy for lung cancer: a secondary analysis of data from the American College of Surgeons Oncology Group Z0030 randomized clinical trial. J Thorac Cardiovasc Surg. 2010;139(4):976-81. https://doi.org/10.1016/j.jtcvs. 2009.11.059 (discussion 981-3).

5. Paul S, Altorki NK, Sheng S, Lee PC, Harpole DH, Onaitis MW, et al. Thoracoscopic lobectomy is associated with lower morbidity than open lobectomy: a propensity-matched analysis from the STS database. J Thorac Cardiovasc Surg. 2010;139(2):366-78. https://doi.org/10. 1016/j.jtcvs.2009.08.026.

6. National Comprehensive Cancer Network. Non-Small Cell Lung Cancer (Version 7.2019). https://www.nccn.org/professionals/physician_gls/ pdf/nscl.pdf. Accessed 15 Sep 2020.

7. Nakano T, Tetsuka K, Endo T, Kanai Y, Otani S, Tsubochi H, et al. Extraction bag lavage cytology during video-assisted thoracoscopic surgery for primary lung cancer. Interact Cardiovasc Thorac Surg. 2014;18(6):770-4. https://doi.org/10.1093/icvts/ivu032.

8. Fiorelli A, Sagan D, Mackiewicz L, Cagini L, Scarnecchia E, Chiodini P, et al. Incidence, risk factors, and analysis of survival of unexpected N2 disease in stage I non-small cell lung cancer. Thorac Cardiovasc Surg. 2015:63(7):558-67. https://doi.org/10.1055/s-0034-1399764.

9. Denlinger CE, Fernandez F, Meyers BF, Pratt W, Zoole JB, Patterson $G A$, et al. Lymph node evaluation in video-assisted thoracoscopic lobectomy versus lobectomy by thoracotomy. Ann Thorac Surg. 2010;89(6):1730-5. https://doi.org/10.1016/j.athoracsur.2010.02.094 (discussion 1736)

10. Cho S, Song $\mathrm{H}$, Yang HC, Kim K, Jheon S. Predictive factors for node metastasis in patients with clinical stage I non-small cell lung cancer. Ann Thorac Surg. 2013;96(1):239-45. https://doi.org/10.1016/j.athor acsur.2013.03.050.

11. Koike T, Koike T, Yamato Y, Yoshiya K, Toyabe S. Predictive risk factors for mediastinal lymph node metastasis in clinical stage IA non-small-cell lung cancer patients. J Thorac Oncol. 2012;7(8):1246-51. https://doi. org/10.1097/JTO.0b013e31825871de.

12. Moon Y, Choi SY, Park JK, Lee KY. Risk factors for occult lymph node metastasis in peripheral non-small cell lung cancer with invasive component size $3 \mathrm{~cm}$ or less. World J Surg. 2020;44(5):1658-65. https://doi. org/10.1007/s00268-019-05365-5.

13. Kaseda K, Asakura K, Kazama A, Ozawa Y. Risk factors for predicting occult lymph node metastasis in patients with clinical stage i non-small cell lung cancer staged by integrated fluorodeoxyglucose positron emission tomography/computed tomography. World J Surg. 2016;40(12):2976-83. https://doi.org/10.1007/s00268-016-3652-5.

14. Bu L, Li Y, Yang F, Zhao H, Jiang GC, Li JF, et al. Completely videoassisted thoracoscopic lobectomy versus open lobectomy for non-small cell lung cancer greater than $5 \mathrm{~cm}$ : a retrospective study. Chin Med J (Engl). 2012;125(3):434-9.

15. Nakano T, Endo S, Endo T, Otani S, Tsubochi H, Yamamoto S, et al. Surgical outcome of video-assisted thoracoscopic surgery vs. thoracotomy for primary lung cancer $>5 \mathrm{~cm}$ in diameter. Ann Thorac Cardiovasc Surg. 2015;21(5):428-34. https://doi.org/10.5761/atcs.oa.15-00014.

16. Burt BM, Leung AN, Yanagawa M, Chen W, Groth SS, Hoang CD, et al. Diameter of solid tumor component alone should be used to establish t stage in lung adenocarcinoma. Ann Surg Oncol. 2015;22(Suppl 3):S1318-23. https://doi.org/10.1245/s10434-015-4780-0.

17. Rami-Porta R, Bolejack V, Crowley J, Ball D, Kim J, Lyons G, et al. The IASLC lung cancer staging project: proposals for the revisions of the T descriptors in the forthcoming eighth edition of the tnm classification for lung cancer. J Thorac Oncol. 2015;10(7):990-1003. https://doi.org/ 10.1097/JTO.0000000000000559.

18. Yoshizawa A, Motoi N, Riely GJ, Sima CS, Gerald WL, Kris MG, et al. Impact of proposed IASLC/ATS/ERS classification of lung adenocarcinoma: prognostic subgroups and implications for further revision of staging based on analysis of 514 stage I cases. Mod Pathol. 2011;24(5):653-64. https://doi.org/10.1038/modpathol.2010.232.

19. Tsutani Y, Miyata Y, Nakayama H, Okumura S, Adachi S, Yoshimura M, et al. Prognostic significance of using solid versus whole tumor size on high-resolution computed tomography for predicting pathologic malignant grade of tumors in clinical stage IA lung adenocarcinoma: a multicenter study. J Thorac Cardiovasc Surg. 2012;143(3):607-12. https://doi.org/10.1016/j.jtcvs.2011.10.037.

20. Maeyashiki T, Suzuki K, Hattori A, Matsunaga T, Takamochi K, Oh S. The size of consolidation on thin-section computed tomography is a better predictor of survival than the maximum tumour dimension in resectable lung cancer. Eur J Cardiothorac Surg. 2013;43(5):915-8. https://doi. org/10.1093/ejcts/ezs516.

21. Goldstraw P, Chansky K, Crowley J, Rami-Porta R, Asamura H, Eberhardt $W E$, et al. The IASLC lung cancer staging project: proposals for revision of the TNM stage groupings in the forthcoming (eighth) edition of the TNM classification for lung cancer. J Thorac Oncol. 2016;11(1):39-51. https://doi.org/10.1016/j.jtho.2015.09.009.

22. Chansky K, Detterbeck FC, Nicholson AG, Rusch VW, Vallieres E, Groome $P$, et al. The IASLC lung cancer staging project: external validation of the revision of the TNM stage groupings in the eighth edition of the TNM classification of lung cancer. J Thorac Oncol. 2017;12(7):1109-21. https://doi.org/10.1016/j.jtho.2017.04.011.

23. Sagawa M, Sato M, Sakurada A, Matsumura Y, Endo C, Handa M, et al. A prospective trial of systematic nodal dissection for lung cancer by video-assisted thoracic surgery: can it be perfect? Ann Thorac Surg. 2002;73(3):900-4. https://doi.org/10.1016/s0003-4975(01)03409-9.

24. Palade E, Passlick B, Osei-Agyemang T, Gunter J, Wiesemann S. Videoassisted vs open mediastinal lymphadenectomy for Stage I nonsmall-cell lung cancer: results of a prospective randomized trial. Eur J Cardiothorac Surg. 2013;44(2):244-9. https://doi.org/10.1093/ejcts/ ezs668 (discussion 249)

25. Watanabe A, Mishina T, Ohori S, Koyanagi T, Nakashima S, Mawatari T, et al. Is video-assisted thoracoscopic surgery a feasible approach for clinical N0 and postoperatively pathological N2 non-small cell lung cancer? Eur J Cardiothorac Surg. 2008;33(5):812-8. https://doi.org/10. 1016/j.ejcts.2008.01.064

26. Watanabe A, Koyanagi T, Ohsawa H, Mawatari T, Nakashima S, Takahashi N, et al. Systematic node dissection by VATS is not inferior to that through an open thoracotomy: a comparative clinicopathologic retrospective study. Surgery. 2005;138(3):510-7. https://doi.org/10. 1016/j.surg.2005.04.005.

27. D'Amico TA, Niland J, Mamet R, Zornosa C, Dexter EU, Onaitis MW. Efficacy of mediastinal lymph node dissection during lobectomy for lung cancer by thoracoscopy and thoracotomy. Ann Thorac Surg. 2011;92(1):226-31. https://doi.org/10.1016/j.athoracsur.2011.03.134 (discussion 231-2).

28. Yang CJ, Kumar A, Deng JZ, Raman V, Lui NS, D'Amico TA, et al. A national analysis of short-term outcomes and long-term survival following thoracoscopic versus open lobectomy for clinical stage II non-small-cell lung cancer. Ann Surg. 2021;273(3):595-605. https://doi. org/10.1097/SLA.0000000000003231. 
29. Amin MB, Edge SB, Greene FL, Byrd DR, Brookland RK, Washington MK, et al. AJCC cancer staging manual. 8th ed. New York: Springer; 2018.

\section{Publisher's Note}

Springer Nature remains neutral with regard to jurisdictional claims in published maps and institutional affiliations.

- fast, convenient online submission

- thorough peer review by experienced researchers in your field

- rapid publication on acceptance

- support for research data, including large and complex data types

- gold Open Access which fosters wider collaboration and increased citations

- maximum visibility for your research: over $100 \mathrm{M}$ website views per year

At BMC, research is always in progress.

Learn more biomedcentral.com/submissions 